\title{
A Pretreatment Method for Analysing Albendazole by HPLC in Plant Material
}

\author{
D. Marciocha $\cdot$ J. Kalka $\cdot$ J. Turek-Szytow $\cdot$ \\ J. Surmacz-Górska
}

Received: 20 March 2013 / Accepted: 4 July 2013 / Published online: 30 July 2013

(C) The Author(s) 2013. This article is published with open access at Springerlink.com

\begin{abstract}
Albendazole (ALB) belongs to a group of benzimidazoles-classified as antiparasitic pharmaceuticals. Its widespread application results in the presence of this pharmaceutical in natural environment (water and soil). In this paper a suitable pretreatment method was established including sampling, freezedrying and extraction. Vicia faba was used as model organism. ALB accumulation by plant tissues was observed in hydroponic culture as well as in soil. The range of pharmaceutical concentrations was $1.7 \times 10^{-5} \mathrm{~mol} / \mathrm{L}$ (in hydroponic culture) and $1.7 \times 10^{-5}$ to $1.7 \times 10^{-4} \mathrm{~mol} / \mathrm{kg}$ air dry soil (in soil). Observations were conducted for 14 days. After this time biological material was freezedried and after homogenization, dimethyl sulfoxide (DMSO) extraction was performed. The recovery of ALB for the roots was $93 \%$ while for the shoots $86 \%$. After cleaning, the samples were subjected to further analysis by HPLC system. Phosphate buffer and acetonitrile (50:50) were used as a mobile phase. Drug retention time was $6.3 \mathrm{~min}$. Results obtained in this experiment indicate higher drug accumulation in roots rather than in
\end{abstract}

D. Marciocha $\cdot$ J. Kalka $\cdot$ J. Turek-Szytow $\cdot$

J. Surmacz-Górska

Silesian University of Technology,

Akademicka 2, 44-100 Gliwice, Poland

D. Marciocha $(\bowtie)$

VŚB-Technical University of Ostrava,

17. listopadu 15/2172, 708-33 Ostrava-Poruba,

Czech Republic

e-mail: d.marciocha@wp.pl the hypocotyl part of the plant, cultivated both in soil and in hydroponic culture.

Keywords Albendazole $\cdot$ Plant $\cdot \mathrm{HPLC} \cdot$ Sample preparation

\section{Introduction}

The need to produce foodstuffs, including those of animal origin, grows in line with expanding human population worldwide. The civilization development led to the organisation of large-scale animal breeding farms in which already one ill specimen might cause decimating the herd. This is the reason why prevention and treatment methods, in case of sickness, are widely applied to the entire herd (Kümmerer 2008). This also causes vast quantities of veterinary pharmaceutical substances being used throughout the European countries (Kools et al. 2008), the effect of which is the biologically active substances penetrating into the environment with, inter alia, animal urine and faeces (Boxall et al. 2002; Kools et al. 2008). Both the growing environmental awareness in humans and the new analytical opportunities to detect the trace substances in the environment led to increasing interest not only in the pharmaceutical substances remaining in animal tissues but also their presence in the natural environmental components such as, for example, surface waters or soil (Kümmerer 2008). Drugs taken in large doses are potentially dangerous for the environment. They include the following therapeutic groups: antibiotics, analgesic, 
antidiabetic, antimalarial, cardiovascular and antiparasitic drugs. Special attention should be paid to veterinary pharmaceuticals which are excreted with faeces or urine due to the possibility of their direct impact on ecosystems. Albendazole belongs to a group of compounds with potential ecological significance, and it is perceived as a soil contaminant (Germer and Sinar 2010; Wang et al. 2009). The albendazole is a benzimidazole carbamate widely applied all over the world (Brunton et al. 2007). It may be used for the treatment of animals affected by mature and juvenile nematodes and tapeworms of the Moniezia genus, and it also acts against sheep liver fluke (in large doses). This drug is well tolerated by cattle and administered therefore in doses amounting to $7.5 \mathrm{mg} / \mathrm{kg}$ body mass and $5 \mathrm{mg} / \mathrm{kg}$ body mass for sheep (Roliński 2001). However, its practical insolubility in water poses restriction on both the use of and the opportunity to administer this drug (chemicalland21 2013). Albendazole solubility increases along with decreasing $\mathrm{pH}$. Good results are also obtained when applying the co-solvents (Torrado 1996).

It is usually unclear what impact the pharmaceutical industry exerts and what happens to pharmacological residues on the agricultural land (WHO 2006). In the subject literature, there are many publications on the determination of albendazole in animal tissues or plasma and in medical preparations or in animal products, such as cheese or milk (Wanyika et al. 2011; Fletouris et al. 1997; Imitrios et al. 2005; Wilson et al. 1991); however, there are fewer publications concerning determination of the drug in water (Cacho et al. 2009, Escher et al. 2008), and there is no available information on determination of the drug in soil or plants. The techniques dedicated to the determination of albendazole are usually for the HPLC method, although there are also methods using GC, ion pair liquid chromatography, UV spectrophotometer or capillary electrophoresis (Fletouris et al. 1996; Wilson et al. 1991; Imitrios et al. 2005; Basavaiah and Negeowda 2004; Prochazkova et al. 2000). In order to obtain an analyte, liquid-liquid extraction is performed, usually with the use of ethyl acetate or acetonitrile, and later with hexane or petrol. Acidification of the environment is also applied, or a co-solvent is added which, in this case, is methanol (Zeugin et al. 1990; Adar et al. 2003; Fletouris et al. 1997; Basaviah and Nagegowda 2004; Torres-Padrón et al. 2010; Wanyika et al. 2011).

Choosing or developing an appropriate methodology for the determination of pharmaceutical substances in environmental samples is very difficult because of the diversity of the matrix, from which the small amounts of analytes are extracted, and due to the variety of their properties. For the biological tests, additional difficulties also appear that relate to the occurrence of proteins, fats and saccharides, which hinder the detection process (Beyer and Biziuk 2007). This study presents a methodology for extraction from and determination of the albendazole in plant material with the application of White Windsor broad bean (Vicia faba major) as the model plant. In the study, dimethyl sulfoxide (DMSO) was used as an extractor in order to obtain analyte from the biological material, and one-step solid-liquid extraction was performed. The extractor used is an excellent solvent for albendazole, and the matrix received enabled direct determination with the use of the HPLC system.

Due to lack of literature data regarding concentration of the studied drug in soil, it is difficult to compare the possible levels of albendazole contamination used in the studies and the real values present in the environment. However, considering the fact that the plasma absorption of the drug is 20 to $50 \%$ of the administered dose, depending on the kind of the animal treated, 80 to $50 \%$ of albendazole will be excreted in unchanged form to the environment (Dayan 2003). As treatment on farms is collective for prophylactic purposes, in the therapeutic periods the drug concentrations in soil can be high, of the order of milligrams per kilogram of soil. The calculation for potential drug concentration in soil conducted by the authors indicated a value of $1.7 \times 10^{-5} \mathrm{~mol} / \mathrm{kg}$ of soil. The worst scenario was assumed in the simulation, i.e. the contamination level after treatment. The data pertain to 150 hens and 1 ha of an ecological farm. As it is widely known, plants very often have the ability to uptake metals, pharmaceutical substances and pesticides from the environment. The presence of pharmaceutical substances in the soil may cause disturbances in vegetation growth or irregularities of their photosynthesis processes. Evaluation of the toxic impacts from pharmaceutical substances on live organisms jointly, with the possibility to simultaneous test the uptake of such substances by the given organism, provides for, inter alia, drawing up the Environmental Risk Assessment Reports (EMEA 2007).

\section{Materials and Methods}

The White Windsor broad bean ( $V$. faba major) produced by Vilmorin is the plant used for these tests. It was chosen since it is a species of a crop that is widely distributed and frequently consumed. Plants of the 
Fabaceae family are used as test plants because they show sensitivity to soil pollutants (Migliore et al. 2003). They also feature relatively fast growth that provides for rapid acquisition of the test material.

Albendazole (purity of $>99 \%$ ), as purchased from the Sigma-Aldrich, was the substance determined. Table 1 shows the basic data on this drug.

"Biohumus forte" mineral organic fertiliser produced by Agrecol was used in accordance with the manufacturer's recommendations $\left(2 \mathrm{~cm}^{3} / \mathrm{dm}^{3}\right)$ for plant-breeding in hydroponic culture and land cultivation. In addition, soil featuring the following parameters was used for in-soil cultivation:

- $\mathrm{pH}$ in aqueous solution - 4.7, in $\mathrm{KCl}-4.4$

- Organic carbon content $1.1 \%$

- Absence of inorganic carbon

- Conductivity in aqueous solution $5.5 \mathrm{mS} / \mathrm{cm}$, in $\mathrm{KCl} 106 \mathrm{mS} / \mathrm{cm}$

- Water-holding capacity $4.8 \times 10^{-1} \mathrm{~cm}^{3} / \mathrm{g}$

Soil humidity during the experiment was maintained at the level of about $30 \%$. Plant cultivation, after sprouting of the seeds, was carried out for 14 days.

\subsection{Experimental Design}

Figure 1 shows the general procedure of the methodology developed for determination of the ALB with the V. faba major plant material.

In order to develop the methodology for determination of the drugs in plants, a hydroponic culture was started without any drug in a breeding medium (water+ fertilizer) that provided for acquisition of the plant material for the preliminary test. This material was used to obtain the (background) extract from the plant matrix tested allowing for detection of the drug and determination of its recovery rate. The seeds purchased were soaked for 3 days to allow appropriate swelling and then cultivated in moistened cotton wool. The plant, the rootlength of which reached approximately $5 \mathrm{~mm}$ was placed onto a polystyrene foam plate with holes drilled therein to allow the roots to contact the breeding medium. The polystyrene foam plate was put onto a watertable $(1 \mathrm{~L})$ in a glass reactor, total volume $1.5 \mathrm{~L}$. For insoil cultivation, the plants were prepared in an identical way with a difference that once sprouted, they were replanted into soil $(1 \mathrm{~kg})$ in an identical reactor. For both hydroponic and ground cultures, the reactors were positioned in the phytotron set to a 16-h day cycle and an 8-h

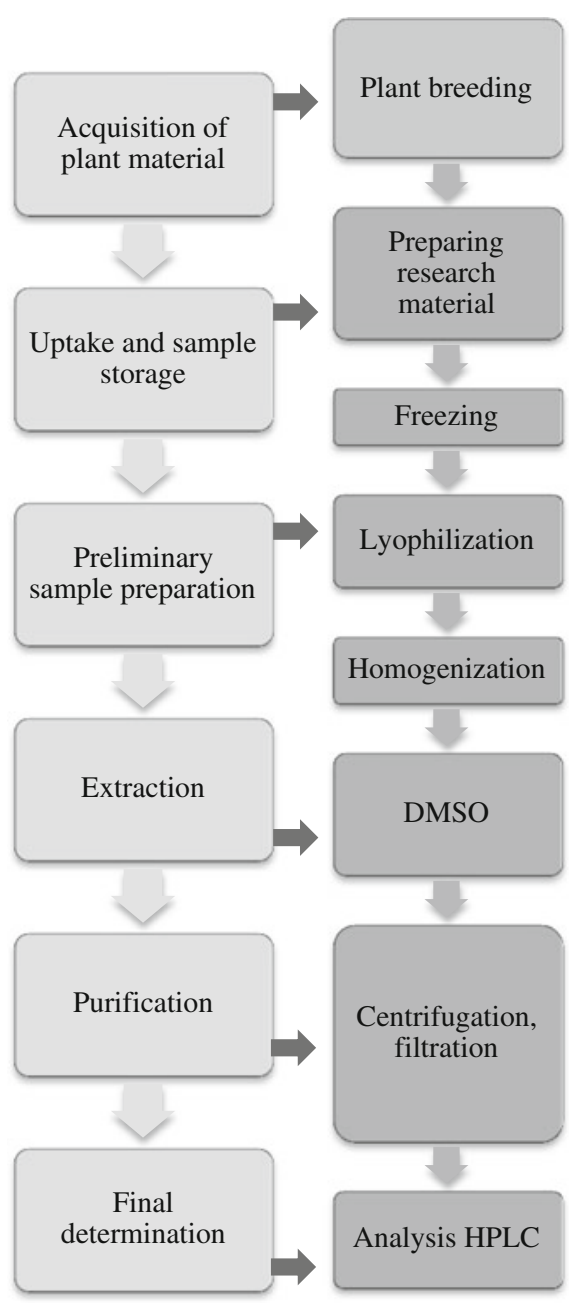

Fig. 1 Outline of the methodology developed for determination of the ALB

night cycle and can be reached by fluorescent light with an intensity of 7,000 $\mathrm{lx}$ at the temperature of $20 \pm 1^{\circ} \mathrm{C}$ in order to provide the appropriate conditions ensuring proper photosynthesis in the plants. The experiments carried out are presented in Table 2.

The output drug concentration, i.e. $3.8 \times 10^{-7}$, $1.9 \times 10^{-6}$, and $3.8 \times 10^{-6} \mathrm{~mol} / \mathrm{dm}^{3}$, assumed for hydroponic cultures, gave no expected results, since the attempt to determine the drug in plant material failed. In order to confirm the preliminary tests (accumulation in roots was $-1.1 \times 10^{-7}$ and above-ground part $1.5 \times 10^{-8}$ ), with contamination of $1.9 \times 10^{-5}$ and incubation period of 28 days until later tests in which the incubation period was shortened to 14 days, the drug concentration was increased up to $1.7 \times 10^{-5} \mathrm{~mol} / \mathrm{L}$. The $1 \mathrm{~cm}^{3}$ per $1 \mathrm{DMSO}$ was used as the co-solvent to increase the drug's 
Table 1 Characteristics of ALB

\begin{tabular}{ll}
\hline IUPAC name & Methyl $N$-[6-(propylsulfanyl)-1H-1,3-benzodiazol-2-yl]carbamate ${ }^{\mathrm{a}}$ \\
\hline Formula $^{\mathrm{a}}$ & $\mathrm{C}_{12} \mathrm{H}_{15} \mathrm{~N}_{3} \mathrm{O}_{2} \mathrm{~S}$ \\
Structural formula & $265.331 \mathrm{~g} / \mathrm{mol}$ \\
Molar mass $^{\mathrm{b}}$ & Solid state \\
Physical state $^{\mathrm{a}}$ & 3.14 \\
${\text { Log } K_{\text {ow }}}^{\mathrm{a}}$ & Practically insoluble \\
Solubility in water $^{\mathrm{a}}$ & $208-210{ }^{\circ} \mathrm{C}$ \\
Melting point $^{\mathrm{a}}$ &
\end{tabular}

${ }^{\mathrm{a}}$ chemicalland21 (2013)

${ }^{\mathrm{b}}$ Escher et al. (2008)

availability. The application of the co-solvent was done to obtain albendazole concentration in water at about $1.1 \times 10^{-6} \mathrm{~mol} / \mathrm{dm}^{3}$, whereas in-soil breeding, it made even distribution of the drug throughout the soil mass easier. Contaminations applied in soil cultures included theoretical potential drug concentration in soil, and the same value was increased by a factor of 10 in order to verify if the drug intake would be proportionate to the concentration. In parallel to the course of the experiments, a control breeding was also performed without any drug content.

\subsection{Extracting the Drug from Plant}

The single-phase extraction of biological material with DMSO was carried out. To this end, $0.2 \mathrm{~g}$ of root and $0.5 \mathrm{~g}$ of lyophilised above-ground plant parts and $10 \mathrm{~cm} 3$ of DMSO were introduced into $15 \mathrm{~cm}^{3}$ tubes and shaken for $90 \mathrm{~min}$. Then the solid parts were centrifuged and further filtered through glass fibre filters with $0.2-\mu \mathrm{m}$ pores.
The research methodology presented above is the final result of the earlier tests to establish the simplest possible and the most effective technique to extract albendazole from the plant material $V$. faba major. Acquisition of dry biomass was made through lyophilisation process. Given the decomposition of the substance tested that occurred under the temperature impact, no drying in $105^{\circ} \mathrm{C}$ temperature could be applied. Then homogenization of the biological material in porcelain mortar was carried out. Extraction from the solid phase (biological material) into the liquid phase (organic solvent) was the next step performed with the aim of acquisition of the background that must not be conflicting with the drug retention time.

Albendazole is a substance poorly or even very poorly soluble in various solvents. DMSO (chemicalland21 2013) is a solvent that features a high affinity with the drug in question. The DMSO dissolves also a wide range of other compounds. Therefore, it was decided that the two-phase extraction would be carried out in order to obtain the background, featuring the lowest possible contents of chemical compounds capable of disrupting detection performed by the HPLC method. The first extraction was
Table 2 The experiments performed

${ }^{\text {a }}$ Experiment in which determination of the drugs concentration in plant material failed

\begin{tabular}{|c|c|c|c|c|c|}
\hline Drug & Concentration, $\mathrm{mol} / \mathrm{dm}^{3}(\mathrm{~mol} / \mathrm{kg})$ & $\begin{array}{l}\text { Duration of the } \\
\text { experiment, days }\end{array}$ & $\begin{array}{l}\text { Number of } \\
\text { repetitions }\end{array}$ & $\begin{array}{l}\text { DMSO, } \\
\mathrm{cm}^{3}\end{array}$ & $\begin{array}{l}\text { Fertilizer, } \\
\mathrm{cm}^{3}\end{array}$ \\
\hline \multicolumn{6}{|c|}{ Screening test-hydroponic culture } \\
\hline ALB & $01.9 \times 10^{-5}$ & 28 & 1 & - & 2 \\
\hline \multicolumn{6}{|c|}{ Definitive test-hydroponic culture } \\
\hline $\mathrm{ALB}^{\mathrm{a}}$ & 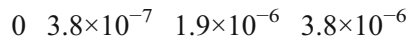 & 14 & 1 & - & 2 \\
\hline ALB & $0 \quad 1.7 \times 10^{-5}-$ & 14 & 3 & 1 & 2 \\
\hline \multicolumn{6}{|c|}{ In-soil experiment } \\
\hline ALB & $\begin{array}{lll}0 & 1.7 \times 10^{-5} \quad 1.7 \times 10^{-4}\end{array}$ & 14 & 3 & 1 & 2 \\
\hline
\end{tabular}


done with acetone. Acetone is a substance commonly used for extracting chlorophyll from the plant material. It is also a solvent which, to only an insignificant degree, dissolves albendazole. When drying of the substance in the open air was completed (acetone makes the analysis impossible due to an intense signal), the second extraction with use of the DMSO was carried out. After purification of the extract, the chromatographic analysis thereof was conducted and it was found that the background obtained does not interfere with the albendazole retention time; however, relatively many peaks were noted in the initial minutes of the analysis that originated most likely from both the trace amounts of non-evaporated acetone and the substances leached out. Then the next step was commenced, namely, the recovery of the drug from the matrix. Extraction was performed in a similar way as before, but $10 \mathrm{mg}$ of the pharmaceutical substance was also weighted out into the samples. However, the HPLC analysis showed no trace of the drug's presence. On the basis of the results obtained, it was decided to make an attempt to carry out a single-phase extraction of biological material with the use of DMSO. After the analysis, the chromatogram showed large signals originating from the background; however, it did not interfere with the drug under determination, as shown in Fig. 2a, b for both the root and the aboveground parts, respectively. For comparison, the chromatogram of pure albendazole is shown in Fig. 2c, as dissolved in DMSO, whereas Fig. 2d presents an example of chromatogram for the root part extract obtained from plants bred in hydroponic culture, where the ALB concentration was $1.7 \times 10^{-5} \mathrm{~mol} / \mathrm{dm}^{3}$.

The next step included determination of the drug recovery from plants that provided information about the maximum drug mass which can be recovered from the matrix. Such information was obtained as a result of adding a known quantity of pharmaceutical substance $\left(1.7 \times 10^{-5}\right.$ mol drug per $\mathrm{kg}$ of lyophilised plant mass) to lyophilised biological material $(0.2 \mathrm{~g}$ of the root and $0.5 \mathrm{~g}$ of the above-ground plant part) and the subsequent determination of the pharmaceutical substance after the extraction process in the extract obtained. The recovery percentage is an indicator of the unavoidable losses due to adsorption of the drug by the plant biomass.

\subsection{Chemical Analysis}

The determination of both the background and the drug concentrations in plant material was performed with the use of high-performance liquid chromatography system provided with the UVD $340 \mathrm{U}$ detector, as manufactured by the Gynkotek. Its capability provides simultaneous observation of the four wavelengths in the $\mathrm{UV}-\mathrm{vis}$ range and observation of the $2 \mathrm{D}$ and $3 \mathrm{D}$ test substance spectra over the whole UV-vis range. Automatic data recording and processing thereof were performed with the application of Chromeleon software package. The RP-18 chromatography column, with length of $250 \mathrm{~mm}$, as preceded by the RP-18 Hypersil Gold pre-column, with length of $25 \mathrm{~mm}$ and manufactured by Thermo Fisher, was the equipment used for testing. A $1-\mathrm{cm}^{3} / \mathrm{min}$ flow was applied. Just as in the case of other pharmaceutical substances, the mixture of phosphate buffer and acetonitrile proved to be the best eluent (Marciocha et al. 2009) and was applied in the ratio 50:50 for the experiment (15 mmol $\mathrm{K}_{2} \mathrm{HPO}_{4}$, $\mathrm{pH}$ 3.8). Duration of the analysis was $7 \mathrm{~min}$. The mean albendazole retention time of the analyses performed was about $6.3 \mathrm{~min}$. The spectra were recorded at $292 \mathrm{~nm}$ wavelength. The analytic curve applied was obtained for drug dissolved in DMSO at the concentration range $1.8 \times 10^{-6}$ to $1.8 \times 10^{-5} \mathrm{~mol}$ albendazole $/ \mathrm{dm}^{3}\left(R^{2}=0.999\right)$.

\section{The Results}

Using the methodology developed, the assessment of the drug recovery from the plant material was done. The results obtained are presented in Table 3.

The recovery of ALB from plant biomass amounted to 93 and $86 \%$ for root and above-ground parts, respectively.

Once the pure background was obtained in place of the retention time of the pharmaceutical substances and when the percentage of the drug recovery from the plant mass tested was determined, the test was commenced to check whether the plant chosen uptakes albendazole from the breeding medium. The tests performed have proven that the plant has uptaken the drug from the breeding medium. The results obtained are shown in Table 4.

The hydroponic culture, with the drug concentration in the breeding medium assumed as $1.7 \times 10^{-5} \mathrm{~mol} / \mathrm{dm}^{3}$, has shown the accumulation of albendazole in both the above-ground parts and in the roots of the plant. The drug concentration in roots appeared more than six times as much higher than in leaves and stems.

During breeding the White Windsor broad bean in soil with concentration values applied at $1.7 \times 10^{-5}$ and 
$1.7 \times 10^{-4} \mathrm{~mol} / \mathrm{dm}^{3}$, it was found that the accumulation of the pharmaceutical substance occurred only in the plant roots. No peak showing the retention time typical of the albendazole was noted in chromatograms of the extract from the above-ground plant parts. Moreover, the accumulation of albendazole in the plants grown in reactors with drug concentrations of $1.7 \times 10^{-4}$ and $1.7 \times 10^{-5} \mathrm{~mol} / \mathrm{kg}$ was almost identical. Although higher drug concentrations were applied, the drug's lower accumulation in the tissues of plants grown in soil is due to the test substance sorption in soil, thus making the drug unavailable to the broad bean. The higher drug accumulation in the root part results from physical and chemical properties of the ALB. As can be seen from the earlier surveys, the albendazole, due to its poor solubility and the high $K_{\text {ow }}$ coefficient, undergoes mainly root sorption and has not been transported into the higher parts of the plant (Migliore et al. 2003; Schneider 2008).

On the basis of the results obtained (no drug accumulation in plant tissue, at the concentration of

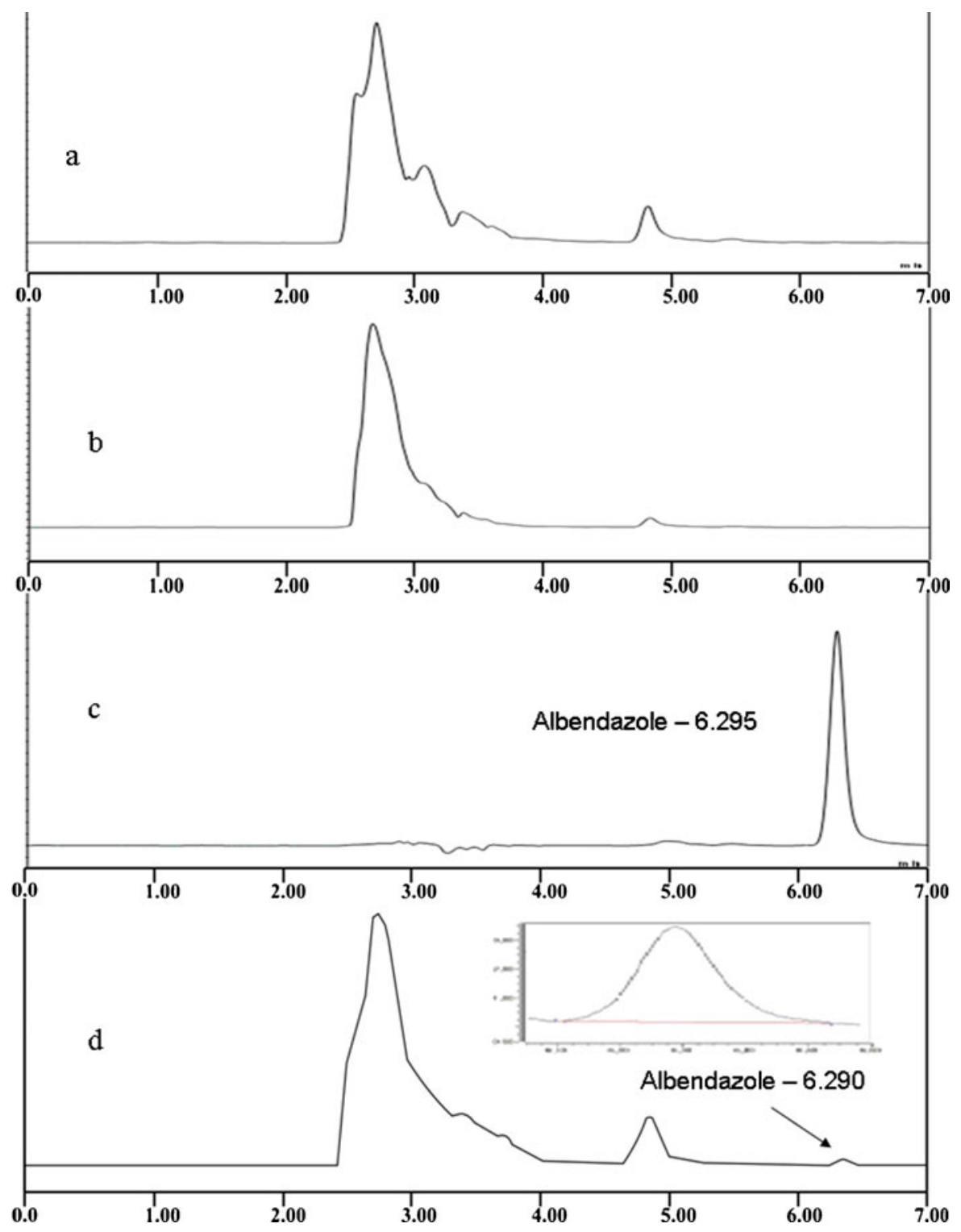

Fig. 2 Chromatogram of the plant extract without the ALB: a for the root part, $\mathbf{b}$ for the above-ground part, $\mathbf{c}$ for the standard dissolved in DMSO, and $\mathbf{d}$ chromatogram of the plant extract with the ALB for the root part from the hydroponic culture 
Table 3 Recovery of albendazole from the matrix

\begin{tabular}{lll}
\hline & Roots & Leaves and sprouts \\
\hline Mean, \% & 92.8 & 86.2 \\
Standard deviation, \% & 1.0 & 1.8 \\
Variation coefficient, \% & 1.4 & 2.9 \\
\hline
\end{tabular}

$3.8 \times 10^{-6}$ in a hydroponic culture after 14 days of incubation), it can be assumed that ALB in an aqueous environment will pose no threat, or such threat will be very small. Low concentration of ALB in water, due to solubility and rapid degradation in natural sunlight (Weerasinghe 1992), suggests that ALB will not be accumulated by plants. However, some questions can be raised regarding the soil environment. For two different levels of contamination (the second contamination level with albendazole was ten times higher than the first one), the drug accumulation in the plant root remained at the same level. Probably the availability of the studied pharmaceutical substance in the soil was at the same level for both contaminations. Most likely, the drug was gradually dissolving in the soil solution which the plant was absorbing. Further studies should be conducted in order to verify if the accumulation increases with a longer vegetative period of the plant and if it influences the plant's general condition.

\section{Summary}

In the methodology developed for determination of the ALB plant material, the advantages (solvent and time savings, reduced analyte losses and the higher extract condensation) of using the single-phase extraction of the drug tested, while applying the DMSO, have prevailed over its drawbacks (high background peaks). Therefore, it was decided to apply the single-phase extraction. Besides ALB, the applied DMSO is capable of coextracting many other substances from plant material which, however, do not interfere with the retention time of the drug detection signal in the final determination by this methodology with the use of HPLC as described here. The recovery of ALB, obtained from the White Windsor broad bean plant material, provides $86 \%$ level of recovery from the matrix for the above-ground part and $93 \%$ for the root parts thereof.

The tests showed that the plant named White Windsor broad bean is capable of accumulation of albendazole uptaken from water and soil. This drug is accumulated in the roots by root sorption (Migliore et al. 2003; Schneider 2008). The maximum concentration in root tissues after hydroponic breeding was $9.8 \times 10^{-8}$ and $2.6 \times 10^{-8} \mathrm{~mol} / \mathrm{g}_{1 \mathrm{~m}}$ following in-soil breeding.

The authors reckon that using DMSO as an extractor could be applied for the determination of ALB not only in broad beans but also in other plants and in fixed assays, such as pharmaceutical products, tissues or soil. Excellent solubility of ALB in DMSO does not require the use of co-solvents or acidification of the environment, therefore resulting in significant transmission of the drug from the solid to liquid phase. Another advantage of the extractor used is that it can be used directly in the analysis employing HPLC or LC-MS system. DMSO is simultaneously used as an extractor and analyte for HPLC. It does not need to be removed, which simplifies the analytic method, without sacrificing the precision of determination.
Table 4 Accumulation of ALB in broad bean

${ }^{\text {a }}$ mole albendazole per gram of lyophilised mass

\begin{tabular}{|c|c|c|}
\hline & Leaves and sprouts & Roots \\
\hline \multicolumn{3}{|c|}{ Albendazole concentration in plant tissue after the hydroponic breeding } \\
\hline Mean concentration of the drug in the tissues, $\mathrm{mol}_{\mathrm{alb}} / \mathrm{g}_{\mathrm{lm}}{ }^{\mathrm{a}}$ & $1.5 \times 10^{-8}$ & $9.8 \times 10^{-8}$ \\
\hline Standard deviation, $\mathrm{mol}_{\mathrm{alb}} / \mathrm{g}_{1 \mathrm{~m}}{ }^{\mathrm{a}}$ & 0.001 & 0.005 \\
\hline Variation coefficient, $\%$ & 12 & 19 \\
\hline \multicolumn{3}{|l|}{ Albendazole concentration in roots of plants in soil breeding } \\
\hline Albendazole concentration in soil, $\mathrm{mol} / \mathrm{kg}_{\mathrm{sm}}$ & $1.7 \times 10-5$ & $1.7 \times 10^{-4}$ \\
\hline Mean concentration of the drug in the roots, $\mathrm{mol}_{\mathrm{alb}} / \mathrm{g}_{\mathrm{lm}}{ }^{\mathrm{a}}$ & $2.3 \times 10^{-8}$ & $2.6 \times 10^{-8}$ \\
\hline Standard deviation, $\mathrm{mol}_{\mathrm{alb}} / \mathrm{g}_{\mathrm{lm}}{ }^{\mathrm{a}}$ & 0.001 & 0.001 \\
\hline Variation coefficient, $\%$ & 17.7 & 18.8 \\
\hline
\end{tabular}


Acknowledgments The authors gratefully acknowledge the financial support provided by Polish research project $\mathrm{N}$ N523 561238. This paper has been elaborated in the framework of the project Opportunity for young researchers, registration no. CZ.1.07/2.3.00/30.0016, and supported by the Operational Programme Education for Competitiveness and co-financed by the European Social Fund and the state budget of the Czech Republic.

Open Access This article is distributed under the terms of the Creative Commons Attribution License which permits any use, distribution, and reproduction in any medium, provided the original author(s) and the source are credited.

\section{References}

Adar, B., Haikh, S., Athan, N., Ummel, R., Enate, R., \& Eimschuessel, R. (2003). Determination of albendazole and its major metabolites in the muscle tissues of Atlantic salmon, tilapia, and rainbow trout by high performance liquid chromatography with fluorometric detection. Journal of Agricultural and Food Chemistry, 51, 3254-3259.

Basavaiah, K., \& Nagegowda, P. (2004). Three new methods for the assay of albendazole using $N$-chlorosuccinimide. Journal of Scientific and Industrial Research, 63, 835-841.

Beyer A., Biziuk M. (2007). Przegląd metod oznaczania pozostałości pestycydów i polichlorowanych bifenyli w próbkach żywności. Ecological Chemistry and Engineering S3 T 14.

Boxall A.B..A., Fogg L., Blackwell P., Kay P., Pemberton E. (2002). Review of veterinary medicines in the environment. Environment Agency R\&D Technical Report P6-012/8TR.

Brunton, L. L., Lazo, J. S., \& Parker, K. L. (2007). Farmakologia Goodmana \& Gilmana (T. 2). Lublin: Czelej.

Cacho, C., Turiel, E., \& Perez-Conde, C. (2009). Molecularly imprinted polymers: an analytical tool for the determination of benzimidazole compounds in water samples. Talanta, 78(3), 1029-1035.

Information service, chemicalland21 (2013) http://www. chemicalland21.com/lifescience/phar/ALBENDAZOLE.htm. Accessed 20 March 2013

Dayan, A. D. (2003). Albendazole, mebendazole and praziquantel. Review of non-clinical toxicity and pharmacokinetics. Acta Tropica, 86, 141-159.

EMEA, European Medicines Agency. (2007). Guideline on environmental impact assessment for veterinary medicinal product. London: EMEA.

Escher, B. I., Berger, C., Bramaz, N., Kwon, J.-H., Richter, M., Tsinman, O., et al. (2008). Membrane-water partitioning, membrane permeability, and baseline toxicity of the parasiticides ivermectin, albendazole, and morantel. Environmental Toxicology and Chemistry, 27(4), 909-918.

Fletouris, D. J., Botsoglou, N. A., Psomas, I. E., \& Mantis, A. I. (1996). Trace analysis of albendazole and its sulphoxide and sulphone metabolites in milk by liquid chromatography. Journal of Chromatography. B, Biomedical Applications, 687(2), 427-435.

Fletouris, D. J., Botsoglo, N. A., Psoma, I. E., \& Mantis, A. I. (1997). Determination of the marker residue of albendazole in cheese by ion-pair liquid chromatography and fluorescence detection. Journal Of Dairy Science, 80(11), 2695-2700.
Germer, J., \& Sinar, E. (2010). Pharmaceutical consumption and residuals potentially relevant to nutrient cycling in Greater Accra, Ghana. Journal of Agriculture and Rural Development in the Tropics and Subtropics, 111(1), 41-53.

Imitrios, D., Letouris, J. F., Lias, E., Apapanagiotou, P. P., Imitrios, D., Akos, S. N., et al. (2005). Highly sensitive ion pair liquid chromatographic determination of albendazole marker residue in animal tissues. Journal of Agricultural and Food Chemistry, 53, 893-89.

Kools, S. A. E., Moltmann, J. F., \& Knacker, T. (2008). Estimating the use of veterinary medicines in the European Union. Regulatory Toxicology and Pharmacology, 50(1), 59-65.

Kümmerer, K. (2008). Pharmaceuticals in the environment: sources, fate, effects and risks. Springer, Berlin-Heidelberg.

Marciocha, D., Kalka, J., Turek-Szytow, J., Wiszniowski, J., \& Surmacz-Górska, J. (2009). Oxidation of sulfamethoxazole by UVA radiation and modified Fenton reagent: toxicity and biodegradability of by-products. Water Science and Technology, 60(10), 2555-2562.

Migliore, L., Cozzolino, S., \& Fiori, M. (2003). Phytotoxicity to and uptake of enrofloxacin in crop plants. Chemosphere, 52(7), 1233-1244.

Prochazkova, A., Chouki, M., Theurillat, R., \& Thormann, W. (2000). Therapeutic drug monitoring of albendazole: determination of albendazole, albendazole sulfoxide, and albendazole sulfone in human plasma using nonaqueous capillary electrophoresis. Elektrophoresis, 21, 729-736.

Roliński, Z. (2001). Farmakologia i farmakoterapia weterynaryjna 2. Warszawa: Wydawnictwo Rolnicze i Leśne.

Schneider, R. J. (2008). Fate of pharmaceuticals in the environment and in water treatment systems. CRC Press, 179-198.

Torrado, S. (1996). Formulation parameters of albendazole solution. International Journal of Pharmaceutics, 140(1), 45-50.

Torres-Padrón, M. E., Aufartová, J., Sosa-Ferrera, Z., \& SantanaRodríguez, J. J. (2010). Benzimidazole fungicides in environmental samples: extraction and determination procedures. Fungicides, 305-324.

Wang, Y., Tang, Y., Xu, L. L., \& Diao, X. P. (2009). Ecotoxicolgical effects of albendazole on Eisenia fetida. Ying Yong Sheng Tai Xue Bao, 20(9), 2296-2300.

Wanyika, H. N., Kareru, P. G., Gitu, L. M., Gatebe, E. G., \& Muyemba, B. N. (2011). Quantification of albendazole in dewormer formulations in the Kenyan market. Advances in Applied Science Research, 2(2), 9-13.

Weerasinghe, C. (1992). Aquatic photodegradation of albendazole and its major metabolites. 1. Photolysis rate and half-life for reactions in a tube. Journal of Agricultural and Food Chemistry, 40(8), 1413-1418.

WHO. (2006). Guidelines for the safe use of wastewater, excreta and greywater. Volume 4: excreta and greywater use in agriculture. Geneva, Switzerland: World Health Organization.

Wilson, R. T., Groneck, J. M., Henry, A., \& Rowe, L. D. (1991). Multiresidue assay for benzimidazole anthelmintics by liquid chromatography and confirmation by gas chromatography/selected-ion monitoring electron impact mass spectrometry. Journal of the Association of Official Analytical Chemists, 74, 56-67.

Zeugin, T., Zysset, T., \& Cotting, J. (1990). Therapeutic monitoring of albendazole: a high-performance liquid chromatography method for determination of its active metabolite albendazole sulfoxide. Therapeutic Drug Monitoring, 12, 187-190. 